\title{
Robotik Radikal Prostatektomide Anestezi Deneyimlerimiz
}

\author{
Our Anesthetic Experiences in Robotic Radical Prostatectomy
}

Tuna ŞAHIN, Barış ARSLAN

Adana Şehir Eğitim ve Araştırma Hastanesi Anestezi ve Reanimasyon ABD, Adana, Türkiye

Geliş tarihi: 20.01.2020 Kabul tarihi: 01.06.2020 DOI: 10.17517/ksutfd.677149

\section{Özet}

Amaç: Robotik radikal prostatektomi prostat kanser tedavisinde yaygın olarak uygulanmaktadır. Robot yardımlı laparoskopik radikal prostatektomilerde anestezi yönetimi, hasta yaşı ve profili, operasyon pozisyonu ve süresi nedeniyle özelliklidir. Litotomi, derin Trendelenburg pozisyonu, CO2 pnomoperitonyum nedeniyle kardiyovasküler, respiratuar, nörolojik komplikasyonlar gelişebilir. Bu retrospektif çalışmada robot yardımlı laparoskopik radikal prostatektomi uygulanan hastalardaki anestezi deneyimlerimizi incelemeyi , sonuçlarımızı literarür eşliğinde tartışmayı amaçladık.

Gereç ve Yöntemler: Etik kurul onayı alındıktan sonra 1 Ocak 2018 ve 30 Eylül 2018 tarihleri arasında robot yardımlı laparoskopik radikal prostatektomi uygulanmış 50 hasta değerlendirildi. Hastalara ait demografik veriler, ASA skorlamaları, ek hastalıklar, intraoperatif anestezi ve analjezi yöntemi, gelişen komplikasyonlar, intravenöz verilen sıvı ve kan miktarı, anestezi süresi, cerrahi süresi, yoğun bakımda kalış süresi, hastanede kalış süresi kaydedildi.

Bulgular: Hastaların yaş ortalaması $63.2 \pm 6.2$ yıl idi. Anestezi idamesinde en sık inhalasyon anestezisi ( sevofluran veya desfluran) \pm opioid (remifentanil) kullanıldı̆̆ 1 gözlendi.10 (\% 20) hastada bradikardi görülürken, 2(\%4) hastada hipotansiyon gelişmiş, 2 (\% 4) hastada kan ürünlerine ihtiyaç duyulmuştur. Postoperatif analjezi amaçlı kullanılan ilaçlar tramadol, parasetemol, nonsteroidal antienflamatuar ilaç (NSAİ́), meperedin idi.Hastaların tamamı operasyon masasında extübe edilerek yakın takip amaçlı yoğun bakım ünitesine alındı. Hastaların \%96 sı bir gece yoğun bakımda takip edilirken, hastanede kalış süresi $4.02 \pm 1.6$ gündü.

Sonuç: Robot yardımlı laparoskopik radikal prostatektomilerde anestezi yönetimi özellikli bir süreçtir. Olası komplikasyonlar için gerekli önlemleri almak, uygun anestezik ajan seçimi, akciğer koruyucu ventilasyon uygulamaları, cerrahi ekip ile koordinasyon anestezi açısından elzemdir.

Anahtar Kelimeler: Prostat kanseri, prostatektomi, anestezi

\section{Abstract}

Objective: Robotic radical prostatectomy is commonly used in prostat cancer treatment. Anesthesia management in Robot-assisted laparoscopic radical prostatectomi eshasspecialty due to patient's age and comorbid diseases, positions and durations of the operation. In this retrospective study we aimed to investigate our anesthesia experiences in patients who underwent Robot-assisted laparoscopic .radical prostatectomy and to discuss the current literature.

Material and Methods: After approval of ethical committee 50 patients who underwent Robot-assisted laparoscopic radical prostatectomy were investigated between 1 January 2018 and 30 September 2018. Demographic data, ASA scores, comorbidities, intraoperative anesthesia and analgesia management, complications, amounts of fluids and bloods given intravenously, anesthesia duration, surgical duration, duration of intensive care unit and hospital stays were recorded.

Results: Average age of the patients was $63.2 \pm 6.2$ years. Inhalation anesthesia ( sevoflurane or desflurane) \pm opioid (remifentanil) was the most anesthesia maintenance preffered. 10 (\% 20) patient had bradicardia, 2 (\%4) patient had hypotension, 2 (\% 4) patient received blood transfusion. Drugs used for postoperative analgesia were tramadol, paracetamol, nonsteroidal anti-inflammatory drugs (NSAID), meperedine. All of the patients were extubated in the operating room and were admitted to intensive care unit (ICU). 96 $\%$ of patients staye done night in the ICU. Time of hospital stay was $4.02 \pm 1.6$ days.

Conclusion: In Robot-assisted laparoscopic radical prostatectomies anesthesia management is a special process. Taking precautions for complications, choice of suitable anesthetic agents, lung protective strategies, being in concordance with surgical team are essential for anesthesia.

Key words: Prostate cancer, prostatectomy, anesthesia

Yazışma Adresi: Tuna Şahin Adana Şehir Eğitim ve Araştırma Hastanesi Anestezi ve Reanimasyon ABD, Adana, Türkiye Tlf: 5058278365, 


\section{GİRIŞ}

Radikal prostatektomi prostat kanserinde temel küratif tedavi yöntemidir. Geleneksel açık prostatektomi operasyonları yapılmakla birlikte günümüzde radikal prostatektomi laparoskopik ve robotik yöntemlerle de yapılabilmektedir (1).

Robot yardımlı laparoskopik radikal prostatektomi düşük kan kaybı, azalmış kan transfüzyon oranı, düşük komplikasyon oranı, kısalmış hastanede kalış süresi gibi avantajları ile açı radikal prostatektomiye kıyasla artan popülariteye sahiptir (2-4).

Robot yardımlı laparoskopik radikal prostatektomi sınırlı retroperitoneal alanda uygulanması gerektiğinden daha iyi cerrahi görüş sağlamak için batının karbondioksit $\left(\mathrm{CO}_{2}\right)$ ile insüflasyonu (pnömoperitonyum) ve derin Trendelenburg pozisyonu gerekmektedir (5).

Sağladığı avantajların yanı sıra litotomi ve derin Trendelenburg pozisyonu, pnömoperitonyum kombinasyonu vücutta olumsuz kardiyovasküler, respiratuvar ve nörofizyolojik değişikliklere sebep olabilir (6).

$\mathrm{CO} 2$ insüflasyonunun başlangıcında ciddi bradikardi ve asistoli bildirilmiştir (7).

Pnomoperitonyum ve derin Trendelenburg birlikteliği ventriküler dolum basıncını ve pozitif basınçlı ventilasyon s1rasında havayolu basıncını artırır ve bu durum hipoksi, pulmoner ödem ve kalp yetmezliği ile sonuçlanabilir (8). Ayrıca difragmanın yukarı yönlü hareketi pulmoner atelektaziye, azalmış fonksiyonel rezidüel kapasite ve akciğer kompliyansına yol açar $(9,10)$.

Trendelenburg pozisyonu artmış intrakraniyal ve intraokuler basınca neden olur (11). Tüm bu olumsuzluklara ilaveten hastanın uzun süre aynı sabit pozisyonu, cerrahi süresince hastaya sınırlı ulaşım, sürekli monitörizasyon, yakın takip gerekliliği sebebiyle robotik radikal prostatektomide anestezi yönetimi önem arzetmektedir (11).

$\mathrm{Bu}$ retrospektif çalışmada robotik radikal prostatektomi uygulanan hastalardaki anestezik yaklaşım ve deneyimlerin aktarılması ve literatür eşliğinde tartışılması amaçlanmıştır.

\section{GEREÇ ve YÖNTEMLER}

Bu retrospektif çalışmada Adana Şehir Eğitim ve Araştırma Hastanesi Klinik Araştırmalar Etik Kurulunun onayı (Karar No: 299) alındıktan sonra 1 Ocak 2018 ve 30 Eylül 2018 tarihleri arasında Adana Şehir Eğitim ve Araştırma Hastanesi'nde robot yardımlı laparoskopik radikal prostatektomi uygulanan 50 erkek hasta değerlendirildi. Çalışma sırasında Helsinki Bildirgesi'ne uyulmuştur.

İncelemede hasta bilgileri için arşivlenen dosya, anestezi kayıtları, hastanede kullanılan medikal bilgi sisteminden yararlanıldı. Çalışmamızda hastalara ait demografik veriler, preoperatif American Society of Anesthesiologists (ASA) skorlamaları, ek hastalıklar, intraoperatif anestezi ve analjezi yöntemi, kullanılan anestezik ajanlar, gelişen komplikasyon- lar, verilen sıvılar ve miktarı, kan ve kan ürünleri miktarı, anti ödem ilaç kullanımı, anestezi süresi, cerrahi süresi, yoğun bakım ihtiyacı, yoğun bakımda kalış süresi, hastanede kalış süresi kaydedildi.

90/60 mm/Hg'nın altındaki arteriyal kan basıncı: hipotansiyon, dakikada 50 'nin altındaki kalp atım hızı: bradikardi olarak değerlendirildi.

\section{İstatiksel Analiz}

Verilerin analizi SPSS 22.0 (IBM statisticsfor Windows version 17, IBM Corporation, Armonk, New York, USA) paket programıyla yapıldı. Sürekli değişkenlerin dağılımının normal dağılıma uygun olup olmadığı Kolmogorov Smirnov testi ile araştırıldı. Sürekli sayısal değişkenler ortalama $\pm s-$ tandart sapma, kategorik değişkenler ise olgu sayısı ve (\%) şeklinde gösterildi. Niteliksel verilerin karşılaştırılmasında Ki-kare Testi kullanıldı. Sonuçlar \%95 güven aralığında, p $<0,05$ değeri istatistiksel olarak anlamlı kabul edildi.

\section{BULGULAR}

Çalışmada hastaların hiç birine premedikasyon uygulanmadığı gözlendi. Hastalara operasyon masasına alındıktan sonra anestezi indüksiyonu öncesi kalp atım hızı, non-invaziv kan basinc1, elektrokardiyografi (EKG), periferik arteriyel oksijen satürasyonu $\left(\mathrm{SPO}_{2}\right)$ monitörizasyonu uygulandığı tespit edildi. Hastalar entübe edildikten sonra radial arter kateterizasyonu ve monitörizasyonu uygulandığı, vaka süresince arter kan gazı ölçümü yapıldığı, end tidal $\mathrm{CO}_{2}$ ölçümlerinin $\left(\mathrm{ETCO}_{2}\right)$ kaydedildiği gözlendi.

Hastaların yaş ortalaması 63.2 \pm 6.2 yıl idi. 42 hasta ASA 2, 8 hasta ASA 3 idi. Ek hastalıklar hipertansiyon (HT), kronik obstrüktif akciğer hastalığı (KOAH), diyabetes mellitus (DM) ve diğer (koroner arter hastalığ $1(\mathrm{KAH})$, guatr, demans v.s.) olarak sınıflandırıldı. Hastaların demografik özellikleri ve komorbiditeleri Tablo 1' de gösterilmiştir.

HT: Hipertansiyon, KOAH: Kronik obstrüktif akciğer hastalığı, DM: Diyabetes mellitus, KAH: Koroner arter hastalığ1

Hastaların \% 90'inda $(\mathrm{n}=45)$ anestezi idamesinde inhalasyon anestezisi (sevofluran veya desfluran) \pm opioid (remifentanil) kullanılırken, 5 (\% 10) hastada total intravenöz anestezinin (propofol+remifentanil) kullanıldığı görüldü. 10 (\% 20) hastada bradikardi görülürken, 2(\%4) hastada hipotansiyon gelişmiş, 2 (\% 4) hastada ise kan ürünlerine ihtiyaç duyulmuştur. Bradikardi gelişen hastalarda atropin $0.5 \mathrm{mg}$ intravenöz kullanıldığı hipotansiyon için ise $10 \mathrm{mg}$ efedrin intravenöz kullanılarak müdahale edildiği tespit edildi.

6 (\% 12) hastada mannitol tek başına, 37 (\%74) hastada ise deksametazonla birlikte anti-ödem ajan olarak kullanılmıştır. Nöromüsküler bloğun geri çevrilmesinde sugammadeks ve neostigminin eşit oranda kullanıldığı görüldü. Ortalama anestezi süresi $396.8 \pm 62.7$ dakika, ortalama ameliyat süresi 357.2 \pm 62.5 dakikaydı (Tablo 2). 
Tablo 1. Hastaların Özellikleri ve Komorbiditeleri

\begin{tabular}{|l|c|}
\hline Parametre & Ortalama \pm SD \\
\hline Yaş & $63.2 \pm 6.2$ \\
\hline ASA skoru & $\mathrm{n}(\%)$ \\
\hline 2 & $42(84)$ \\
\hline 3 & $8(16)$ \\
\hline Komorbiditeleri & $\mathbf{n}(\%)$ \\
\hline HT & $12(24)$ \\
\hline KOAH & $7(14)$ \\
\hline DM & $4(8)$ \\
\hline Diğer(KAH, guatr,demansv.s) & $5(10)$ \\
\hline Veriler ortalama \pm standart sapma (SD), olgu sayısı (n) ve yüzde (\%) olarak belirtilmiştir.
\end{tabular}

\section{Tablo 2. Intraoperatif ve postoperatif parametreler}

\begin{tabular}{|c|c|}
\hline Parametre & Ortalama \pm SD \\
\hline Anestezi Süresi (dakika) & $396.8 \pm 62.7$ \\
\hline Operasyon Süresi (dakika ) & $357.2 \pm 62.5$ \\
\hline Kolloid solüsyon infüzyonu miktarı (mililitre ) & $410.0 \pm 330.2$ \\
\hline Kristaloid sıvı infüzyonu miktarı (mililitre ) & $2812.0 \pm 630.7$ \\
\hline Yoğun bakımda kalış süresi (gün) & $1.06 \pm 0.2$ \\
\hline Hastanede kalış süresi ( gün) & $4.02 \pm 1.6$ \\
\hline Anestezi idamesi & $\mathrm{n}(\%)$ \\
\hline Propofol+remifentanil & $5(10)$ \\
\hline Sevofluran & $11(22)$ \\
\hline \multicolumn{2}{|l|}{$\begin{array}{l}\text { Sevofluran+remifentanil } \\
27(54)\end{array}$} \\
\hline Desfluran & $3(6)$ \\
\hline Desfluran+remifentanil & $4(8)$ \\
\hline Komplikasyon & $\mathrm{n}(\%)$ \\
\hline Yok & $38(76)$ \\
\hline Bradikardi & $10(20)$ \\
\hline Hipotansiyon & $2(4)$ \\
\hline Cerrahi ile ilişkili komplikasyonlar & $2(4)$ \\
\hline Kan ürünleri kullanımı & $\mathrm{n}(\%)$ \\
\hline Var & $2(4)$ \\
\hline Yok & $48(96)$ \\
\hline
\end{tabular}

Postoperatif analjezi amaçlı genellikle ( $n=36$ hastayla (\%72)) tramadol kullanılırken, 9 (\%18) hastada tramadola ek olarak parasetemol veya NSAIII’lerin kombine edildiği görüldü. 2 hastada sadece meperedin kullanılırken, 11 hastada (\%22) hiçbir analjeziğe ihtiyaç duyulmadığı gözlendi. Hastaların tamamı operasyon masasında ekstübe edilerek yakın takip amaçlı yoğun bakım ünitesine alındı. 48 (96\%) hasta bir gece yoğun bakımda takip edilirken, 2 (4\%) hastanın iki gece yoğun bakımda takibi sürmüştür. Hastaların ortalama yoğun bakımda kalış süresi 1.06£0.2 gün, hastanede kalış sü- resi 4.02 \pm 1.6 gündü (Tablo 2). Uygulanan anestezi idamesi türünün ya da anti-ödem tedavisinin hastanede kalış süresine istatiksel olarak bir etkisinin olmadığı görüldü.

\section{TARTIŞMA}

Robot yardımlı laparoskopik radikal prostatektomilerde anestezi idamesinde hem inhalasyon anestezikleri \pm opioid kombinasyonu hemde total intravenöz anestezikler kullanılmaktadır. Robotik prostatektomilerde sevofluran-remifentanil ile propofol-remifentanilin karşılaştırıldığ 
bir çalışmada her iki grupta $\mathrm{SPO}_{2}$ ve $\mathrm{ETCO}_{2}$ değerlerinin tüm ölçüm zamanlarında benzer olduğu, propofol grubunda daha fazla olmakla birlikte her 2 grupta $\mathrm{PH}$ da azalma olduğu, $\mathrm{ETCO}_{2}$ ve $\mathrm{PaCO}_{2}$ değerlerinin her 2 grupta da $\mathrm{CO}_{2}$ insüflasyonu sonrası arttığı belirtilmiştir. Aynı çalışmada derlenme skorunun ilk 3 saatte propofol-remifentanil grubunda, bulantı kusmanın ise ilk 2 saatte sevofluran-remifentanil grubunda daha yüksek olduğu gözlenmiştir (12). Bizim çalışmamizda anestezi idamesinde inhalasyon anestezikleri \pm opioid kullanımının \% 90 oranında tercih edildiği gözlenmiştir. İnhalasyon ajanı olarak sıklıkla sevofluranın tercih edildiğini, opiod olarak ise kısa etkili remifentanilin kullanıldığ dü.

Robot yardımlı laparoskopik prostatektomilerde uygulanan derin Trendelenburg pozisyonu ve $\mathrm{CO}_{2}$ pnömoperitonyum intrakranial basınçta bazal değere göre $10 \mathrm{mmHg}$ 'lk artışa neden olabilir (13). Çalışmalar göstermiştir ki ultrasonografi eşliğinde optik sinir kılıf çapı ölçümü artmış kafa içi basıncı için noninvaziv ve üretilebilir bir tekniktir (14). Robot yardımlı laparoskopik radikal prostatektomilerde desfluran ve total intravenöz anestezinin optik sinir kılıf çapına etkilerinin karşılaştırıldığı randomize kontrollü bir çalışmada ortalama optik sinir kılıf çapının propofol-remifentanil grubunda desfluran- remifentanil grubuna göre anlamlı olarak daha düşük olduğu bulunmuştur (15). Bu çalışmada total intravenöz anestezinin serebral hipoperfüzyon için risk taş1yan veya intrakraniyal basincı yüksek hastalarda daha uygun bir seçim olabileceği belirtilmiştir. Çalışmamızda total intravenöz anestezinin \%10 oranında tercih edildiği gözlendi. Hiçbir olguda ultrasonografi eşliğinde optik sinir kılıf çapı ölçülmemişti. Antiödem tedavinin 43 hastada uygulandığı görüldü.

Robot yardımlı laparoskopik radikal prostatektomilerde baş ve boyundaki venöz stazın etkisiyle yüzde ve üst havayollarında şişlik ve ödem yaygındır (16). Sınırlayıcı sıvı tedavisi artmış fasiyal ödemi önlemek ve artmış idrar çıkışı ile cerrahi saha görüşünü önlememek adına gerekli olabilir. Robotik prostatektomide anestezinin ele alındığı bir derlemede cerrah veziko üretral anostomozu tamamlayana kadar $800 \mathrm{~mL}$ den daha fazla sivı verilmemesi, sonrasinda ilave 700-1200 $\mathrm{mL}$ sıvı verilmesi önerilmiştir (17). Çalışmamızda anestezi süresi $396.8 \pm 62.7 \mathrm{dk}$,operasyon süresi $357.2 \pm 62.5 \mathrm{dk}$, verilen kolloid sıvı miktarı $410.0 \pm 330.2 \mathrm{~mL}$, kristaloid sıvı miktarı 2812.0 $\pm 630.7 \mathrm{~mL}$ bulunmuştur.

Geleneksel prostatektomi ile karşılaştırıldığında robot yardımlı laparoskopik radikal prostatektominin kan kaybını azalttığı, transfüzyon oranını azalttığı ve hastanede kalış süresini kısalttığ görülmektedir (4). Çalışmamızda 2 hastada kan ürünü ihtiyacı olmuştur. Hastanede kalış süresinin ortalama 4.02 1.6 gün olduğu görülmüştür.

Robot yardımlı laparoskopik radikal prostatektomilerde olası akciğer komplikasyonlarından korunmak için akciğer koruyucu ventilatör stratejilerine ihtiyaç vardır. Derin Trendelenburg pozisyonunun akciğerlere negatif etkisinin üste- sinden gelmek ve atelektaziyi önlemek için tidal volüm 6-8 $\mathrm{mLkg}^{-1}$, expiryum sonu pozitif basınç (PEEP) 4-7 $\mathrm{cmH}_{2} \mathrm{O}$ önerilir. Maksimum havayolu basınc1 $35 \mathrm{cmH}_{2} \mathrm{O}$ altında tutulmalıdir (17).

Kim MS ve arkadaşları yaptıkları robot yardımlı laporoskopik radikal prostatektomilerde basınç kontrollü +volüm garantili ventilasyon ile volüm kontrollü 1:1 eşit orantılı ventilasyon modlarını karşılaştırmışlardır. Her 2 ventilatör modunun robot yardımlı laparoskopik radikal prostatektomi için uygun oldugunu, basınç kontrollü+ volüm garantili modun daha düşük ortalama havayolu basıncı (Pmean) değeri sağlaması nedeniyle kardiyovasküler fonksiyonu azalmış hastalarda daha uygun bir seçenek olabileceğini belirtmişlerdir (18).

Çalışmamızın en önemli kısıtlaması operasyon esnasında uygulanan ventilasyon modları her olgunun anestezi kaydından elde edilemediği için gerekli değerlendirme ve karş1laştırma yapılamamasıdır. Hastaların tamamının operasyon masasında problemsiz ekstübe edildiği gözlendi. Postoperatif takiplerde hiçbir olguda reentübasyon gerekmediği kaydedildi. Arter kan gazı ölçümleri, gerekli ventilatör ayarlamaları ve yakın gözlemin bu duruma katkısı olduğunu düşünmekteyiz.

Sonuç olarak, giderek artan oranda uygulanan robot yardimlı laparoskopik radikal prostatektomilerde anestezinin önemli bir yeri olduğunu düşünmekteyiz. Olası komplikasyonlar için önceden hazırlıklı olmak, gerekli önlemler almak, uygun anestezik ajan seçimi, akciğer koruyucu ventilasyon uygulamaları, cerrahi ekip ile koordinasyonun başarıya götürmede katkısı büyüktür.

Çıkar Çatışması ve Finans Durumu: Çalışmamız bir kurum ve kuruluşça finanse edilmemiştir. Bu çalışmada yazarlar arasında herhangi bir konuda çıkar çatışması bulunmamaktadır.

\section{KAYNAKLAR}

1. Bivalacqua TJ, Pierorazio PM, Su LM. Open, laparoscopic and roboticradical prostatectomy: optimizing the surgical approach. Surgical Oncology. 2009; 18(3): 233-41.

2. Hu JC, Gu X, Lipsitz SR, Barry MJ, D’Amico AV, Weinberg AC, et al. Comparative effectiveness of minimally invasivevs open radical prostatectomy. JAMA. 2009; 302(14): 1557-64.

3. Menon M, Shrivastava A, Tewari A. Laparoscopic radicalprostatectomy: conventional and robotic. Urology. 2005; 66(5): 1014.

4. D’Alonzo RC, Gan TJ, Moul JW, Albala DM, Polascik TJ, Robertson $\mathrm{CN}$, et al. A retrospective comparison of anesthetic management of robot-assisted laparoscopic radical prostatectomy versus radical retropubic prostatectomy. J Clin Anesth 2009; 21(5): 322-8.

5. Gainsburg DM. Anesthetic concerns for robotic-assisted laparoscopic radical prostatectomy. Minerva Anestesiol. 2012; 78(5): 596-604.

6. Awad H, Walker CM, Shaikh M, Dimitrova GT, Abaza R, O’Hara J. Anesthetic considerations for robotic prostatectomy: a review of the literature. J Clin Anesth. 2012; 24(6): 494-504.

7. Gainsburg DM, Wax D, Reich DL, Carlucci JR, Samadi DB. Intra operative management of robotic-assisted versus open radical prostatectomy. JSLS: Journal of the Society of Laparoendoscopic Surgeons. 2010; 14(1): 1-5. 
8. Choi EM, Na S, Choi SH, An J, Rha KH, Oh YJ. Comparison of volume-controlled and pressure-controlled ventilation in steep Trendelenburg position for robot-assisted laparoscopic radical prostatectomy. J Clin Anesth. 2011; 23(3): 183-8.

9. Andersson LE, Baath M, Thorne A, Aspelin P, Odeberg-Wernerman S. Effect of carbondioxide pneumoperitoneum on development of atelectasis during anesthesia, examined by spiral computed tomography. Anesthesiology. 2005; 102(2): 293-9.

10. Ogurlu M, Kucuk M, Bilgin F, Sizlan A, Yanarates O, Eksert S, et al. Pressure-controlled vs volume-controlled ventilation during laparoscopic gynecologic surgery. J Minim Invasive Gynecol. 2010; 17(3): 295-300.

11. Awad H, Santilli S, Ohr M, Roth A, Yan W, Fernandez S, et al. The effects of steep trendelenburg positioning on intraocular pressure during robotic radical prostatectomy. Anesth Analg 2009; 109(3): 473-8.

12. Özdemir M, Bakan N, Şahin ÖT, Kurtçelebi N, Erbeşler ZA, Tunca ST. The Comparison of Sevoflurane-Remifentanyl and Propofol-Remifentanyl in Robotic Prostatectomies. J Clin Anal Med. 2013; 4: 313-7.

13. Verdonck P, Kalmar AF, Suy K, Geeraerts T, Vercauteren M, MottrieA et al. Optic nerves heath diameter remains constant during robot assisted laparoscopic radical prostatectomy. PLoSOne. 2014;9(11): e111916.

14. Geeraerts T, Merceron S, Benhamou D, Vigué B, Duranteau J. Non-invasive assessment of intracranial pressure using ocular sonography in neuro critical care patients. Intensive Care Med. 2008; 34(11): 2062-7.

15. Choi ES, Jeon YT, Sohn HM, Kim DW, Choi SJ, In CB. Comparison of the effects of desflurane and total intravenous anesthesia on the optic nerves heath diameter in robot assisted laparoscopic radical prostatectomy. Medicine. 2018; 97(41): e12772

16. Baltayian S. A brief review: anesthesia for robotic prostatectomy. J Robotic Surg. 2008; 2(2): 59-66.

17. Gupta K, Mehta Y, Sarin Jolly A, Khanna S. Anaesthesia for robotic gynaecological surgery. Anaesth Intensive Care 2012; 40(4): 614-21.

18. Kim MS, Soh S, Kim SY, Song MS, Park JH. Comparisons of Pressure-controlled Ventilation with Volume Guarantee and Volume-controlled 1:1 Equal Ratio Ventilation on Oxygenation and Respiratory Mechanics during Robot-assisted Laparoscopic Radical Prostatectomy: a Randomized-controlled Trial. Int J Med Sci. 2018; 15(13): 1522-9 